\title{
Engineered Peptides for Nanohybrid Assemblies
}

\author{
Urartu Ozgur Safak Seker, ${ }^{\dagger}, \ddagger, \S$ Vijay Kumar Sharma, ${ }^{\ddagger}$ Shahab Akhavan, ${ }^{\ddagger}$ and Hilmi Volkan Demir $*, \dagger, \ddagger$
}

${ }^{\dagger}$ Luminous! Center of Excellence for Semiconductor Lighting and Displays, School of Electrical and Electronic Engineering, School of Physical and Mathematical Sciences, Nanyang Technological University, Nanyang Avenue, Singapore 639798, Singapore

${ }^{\ddagger}$ Departments of Physics, Department of Electrical and Electronics Engineering, and UNAM - Institute of Materials Science and Nanotechnology, Bilkent University, TR-06800 Ankara, Turkey

\section{Supporting Information}

ABSTRACT: Inspired by biological material synthesis, synthetic biomineralization peptides have been screened through a laboratory evolution using biocombinatorial techniques. In this study, using the fine examples in nature, silica binding peptides and gold binding peptides were fused together to form a hybrid peptide. We designed fusion peptides with different gold binding and silica binding parts. First, we have tested the binding capability of the fusion peptides using quartz crystal microbalance on gold surface and silica surface. Second, S1G1 hybrid peptide enabled assembly of gold nanoparticles on a silica surface was achieved. Finally, nanomaterial synthesis ability of the S1G1 peptide was presented by the formation of a silica film on a gold surface. In this study, we are presenting a hybrid peptide tool for nanohybrid assembly as a promising route for nanotechnology applications.

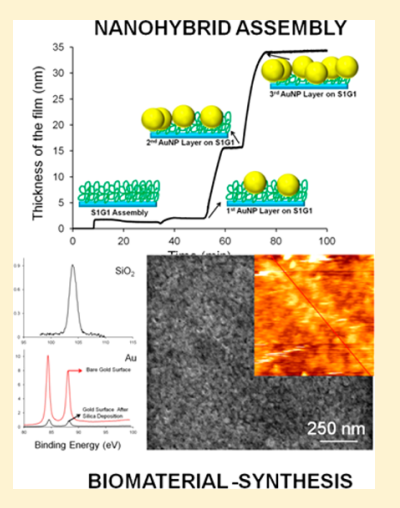

\section{INTRODUCTION}

Self-assembly is a key process in nanotechnology for bottom-up construction of the material systems. ${ }^{1,2}$ Assembly and organization of the materials and molecular systems at the nanoscale are realized by utilizing chemical and physical approaches., Although many developments have been achieved in nanoscience and nanotechnology research, designing molecules for hybrid nanoassembly of the nanoentities on targeted surfaces is still a challenge. To overcome this challenge, biological biomolecules, especially peptides, have been tested as linker molecules to bridge nanomaterial with solid material surfaces through noncovalent interactions. ${ }^{5-7}$ Phage display and cell surface display are commonly utilized biocombinatorial techniques to screen and select peptides specific to materials (e.g., metals, ${ }^{8,9}$ oxides, ${ }^{10,11}$ semiconductors, ${ }^{12}$ minerals, ${ }^{13}$ and polymers ${ }^{14}$ ) to create peptide linkers for targeted nanomaterials assembly ${ }^{15,16}$ and materials synthesis. ${ }^{17,18}$ Material binding peptides were screened and selected to interact with one type of material surface. However, recently, individual material binding peptides were fused through a peptide bond to form a final bifunctional peptide. Bifunctional peptides were utilized for multimaterial assembly, ${ }^{19}$ multimaterial nanostructure formation applications, ${ }^{20,21}$ formation of bioactive surfaces, ${ }^{22}$ and biomineralization. ${ }^{23}$ Although these applications are promising new opportunities for nanotechnology and nanobiotechnology, there is a still need for understanding the true mechanism of the interaction of the bifunctional peptides with their target surfaces. In this study, using the hybrid peptides formed from well-characterized peptides, we carried out quantitative characterization of the bifunctional peptides along with examples of their utilization in nanomaterial assembly and materials synthesis. Biomolecules have been widely used for synthetic biomineralization and selfassembly applications. ${ }^{17,24}$ In this study, a silica forming peptide that was identified as the core silica forming motif from a silaffin protein isolated from a diatom Cylindrotheca fusiformis, dubbed SAP1 (silica affinity peptide 1), was used as silica binding part of the hybrid peptide. ${ }^{25}$ Also another silica binding peptide, SAP2, isolated from a phage displayed peptide library was used for a comparison of their silica binding affinity with SAP1. Gold affinity peptides (GAP1 and GAP2, GAP3) and a cysteine were exploited respectively as the gold binding part of each hybrid peptide. ${ }^{26,27}$ Six different combinations of gold and silica binding peptides were proposed as hybrid multifunctional peptides. We did an affinity screening of combinations for their binding affinity to gold surface and to silica surface. Regarding the affinity test results, S1G1 peptide was identified as the best candidate for further applications. In addition to the molecular binding characterization of the hybrid peptides, we demonstrated the nanomaterial assembly and the material synthesis ability of S1G1. Rational generation of dual functionality material binding peptides and screening of these peptides using molecular binding characterization along with functional studies will open new routes for creation and implementation of biomolecules based material assemblers and synthesizers.

\section{EXPERIMENTAL SECTION}

Chemicals and Peptides. Peptides were synthesized (by Genescript) using Fmoc solid phase peptide synthesis and were

Received: November 22, 2013

Published: February 4, 2014 
purified using reverse phase liquid chromatography to a degree of $95 \%$ purity. Lyophilized peptides were prepared using PBS buffer at the $\mathrm{pH}$ adjusted to 7.5. Gold nanoparticles were purchased from (SigmaAldrich, USA) and silica nanoparticles were purchased from Polysciences, Inc.

Quartz Crystal Microbalance (QCM-D). QCM-D analysis for the adsorption monitoring of the peptides and real time monitoring of the nanoparticles assembly was carried out using a quartz crystal microbalance Q-Sense E1 (from Q-Sense Company, Frolunda, Sweden). QCM-D analysis of the adsorption of the peptides on gold and silica surfaces was carried out by flowing the peptide solutions onto the QCM-D sensors surfaces, which were either gold or silica coated quartz crystals. Commercially available silica/or gold coated QCM-D sensors were purchased from Q-Sense. Prior to the binding analysis of the peptides, sensor surfaces were cleaned as follows. First, sensors were dipped into a solution containing $2 \%(\mathrm{v} / \mathrm{v})$ Hellmanex detergent for $10 \mathrm{~min}$. Sensors were removed and washed thoroughly with ultrapure water. After rinsing, sensors were dried by blowing nitrogen to remove remaining water droplets. Peptide concentrations were adjusted $10,20,40,50$, and $100 \mu \mathrm{M}$. The flow rate of the peptide solution was adjusted to $10 \mu \mathrm{L} / \mathrm{min}$. After each run, for the adsorption of peptides on silica or gold surfaces, weakly bound molecules were removed by excess washing with PBS buffer solutions until the signal reached equilibrium. After each run, the instrument was flushed through with Hellmanex detergent 2\% (v/v) and with DI water.

For the affinity calculations, peptide adsorption isotherms were analyzed using a single exponential Langmuir equation explained in previous work. ${ }^{28}$ Additionally, calculations of adsorbed film thickness of the layer-by-layer assembled peptide-nanoparticle layers were realized using a viscoelastic modeling approach; details and theory of the method are given in the Supporting Information.

Gold Nanoparticle Assembly. Multilayered gold nanoparticle assembly was monitored using QCM-D. First, $100 \mu \mathrm{M}$ of S1G1 peptide dissolved in PBS buffer ( $\mathrm{pH}$ 7.4) was sent over the silica coated sensor surface. Following saturation of the surface with the peptide from the QCM-D signal, nonspecifically and poorly bound peptides were removed from the sensor surface by washing the surface with PBS buffer. Later 25, 50, and $100 \mu \mathrm{M} 15 \mathrm{~nm}$ AuNP particles were flown on the surface; after each step, unbound gold nanoparticles were removed from the surface by excessive washing with PBS buffer. Collected data was analyzed with the Q-Tools software provides along with the QCM-D instrument. Details of the film thickness calculations using the QTools software can be found in the Supporting Information.

Synthesis and Characterization of the Biosilica Film. Biosilica film was formed on $100 \mathrm{~nm}$ gold coated on silicon surface. Gold surface was first cleaned with isopropanol and rinsed with DI water. Then $100 \mu \mathrm{M}$ of S1G1 peptide in PBS buffer was drop-casted on gold surface and incubated in a humidity chamber for $4 \mathrm{~h}$. Loosely bound peptides were removed by rinsing with PBS buffer. Silane precursor was prepared as described earlier. ${ }^{25}$ First, $1 \mathrm{M}$ tetrahydroxysilane was formed by preparing tetramethyl orthosilicate (TMOS) in $1 \mathrm{mM} \mathrm{HCl}$. Next, $1 \mathrm{M}$ tetrahydroxysilane was diluted with phosphate-citrate buffer $(\mathrm{pH}$ 8). Then $100 \mu \mathrm{L}$ of the silane solution was added onto the peptide decorated gold surface and incubated $10 \mathrm{~min}$ for silica formation. Finally, the sample was thoroughly rinsed with DI water. Samples were used for further characterization with atomic force microscopy (AFM), scanning electron microscopy (SEM), and X-ray photoelectron spectroscopy (XPS).

AFM imaging of the samples were conducted with a PSIA-XE-100 instrument under the tapping mode. The images were taken from a 5 $\mu \mathrm{m} \times 5 \mu \mathrm{m}$ area. The recorded images were analyzed using the image analysis program PSIA, and a line profile of the image was plotted using this program. Large area coverage and morphological analysis of the samples was carried out using a FEI Quanta 200 FEG scanning electron microscope, and XPS measurements using a K-Alpha-Thermo instrument.

\section{RESULTS AND DISCUSSION}

Hybrid peptides composed of a gold binding peptide and a silica binding peptide were proposed. They were tested for their binding affinities on a silica surface and on a gold surface. To combine a silica binding peptide with a gold binding peptide, a linker peptide was used to prevent any loss in the affinity of the individual peptides during their interaction with the given solid surface. GSGSG peptide was used as a universal flexible linker for our designs because it is also widely used in peptide display libraries as well as in protein engineering studies. Peptide linkers provide flexibility to the final hybrid peptide sequences while they are bridging them together. The sequence information of the dual functionality peptides and their corresponding nomenclatures are given in Table 1 (a detailed

Table 1. Amino Acid Sequences of the Hybrid Peptides and Their Corresponding Sample Codes

\begin{tabular}{|c|c|c|c|}
\hline hybrid code & SBP-linker- $G B P$ & $\begin{array}{l}\mathrm{pI}(\mathrm{pH} \\
\text { scale })\end{array}$ & $\begin{array}{l}\text { total } \\
\text { charge }\end{array}$ \\
\hline $\begin{array}{l}\text { S1G1 } \\
\quad(\text { SAP1-GAP1) }\end{array}$ & $\begin{array}{l}\text { SSKKSGSYSGSKGSKRRIL- } \\
\text { GSGSG-MHGKTQATSGTIQS }\end{array}$ & 11.2 & +7 \\
\hline $\begin{array}{l}\text { S1G2 } \\
\text { (SAP1-GAP2) }\end{array}$ & $\begin{array}{l}\text { SSKKSGSYSGSKGSKRRIL- } \\
\text { GSGSG-VSGSSPDS }\end{array}$ & 10.5 & +5 \\
\hline S1C (SAP1-C) & $\begin{array}{l}\text { SSKKSGSYSGSKGSKRRIL- } \\
\text { GSGSG-C }\end{array}$ & 10.5 & +6 \\
\hline $\begin{array}{l}\text { S1G3 } \\
\text { (SAP1-GAP3) }\end{array}$ & $\begin{array}{l}\text { SSKKSGSYSGSKGSKRRIL- } \\
\text { GSGSG- } H Н H H H H\end{array}$ & 11.2 & +6 \\
\hline $\begin{array}{l}\text { S2G1 } \\
\text { (SAP2-GAP1) }\end{array}$ & $\begin{array}{l}\text { HPPMNASHPHMH-GSGSG- } \\
\text { MHGKTQATSGTIQS }\end{array}$ & 8.8 & -1 \\
\hline $\begin{array}{l}\text { S1PG1 } \\
\text { (SAP1-P-GAP1) }\end{array}$ & $\begin{array}{l}\text { SSKKSGSYSGSKGSKRRIL- } \\
\text { PGPGP-MHGKTQATSGTIQS }\end{array}$ & 11.2 & +7 \\
\hline
\end{tabular}

list can be found in Table S1 inSupporting Information). The binding affinity of each hybrid peptide to gold surface or silica surface was tested using quartz crystal microbalance with dissipation monitoring (QCM-D), and raw data for binding interactions of the peptides with gold or silica surface is presented in Figure S1 and dissipation data can be found on Figure S2. The adsorption data fitted to a single Langmuir adsorption model of the following hybrid peptides S1G1 and S1PG1 are presented in Figure 1, whereas the adsorption data of S1G2, S1G3, S1C, and S2G1 fitted to the same model as shown in Figure 2. Calculated binding affinity constants and binding free energies of the peptides are presented in Table 2.

Our initial experiments were designed using the S1G1 as the starting peptide. Individual part of the S1G1, gold binding peptide (GAP1) part and silica binding peptide part (SAP1) were previously analyzed. Gold binding affinity of GAP1 was found high using a quantitative approach ${ }^{29}$ whereas its crossspecificity to silica was probed qualitatively and found to be very low. ${ }^{30}$ SAP1 peptide was investigated qualitatively using fluorescence microcopy ${ }^{21}$ and by silica nanoparticle assembly capacity, ${ }^{25}$ similarly its cross-specificity to gold surface was shown very low qualitatively by fluorescence microscopy analyses. $^{21}$

QCM-D studies revealed that S1G1 peptide has a binding affinity constant of $20 \pm 2.5 \mu \mathrm{M}$ to the gold surface and $1 \pm 0.2$ $\mu \mathrm{M}$ to the silica surface. S1G1 peptide has a better binding affinity to silica compared to the gold surface. GAP1 and SAP1 peptides are both positively charged. This is important for the interaction of the peptides with the silica, as silica is negatively charged under the given conditions, in PBS buffer at pH 7 .

The comparison of rigid versus flexible linker usage was tested for its effect on binding affinity. The flexible GGSGSG 

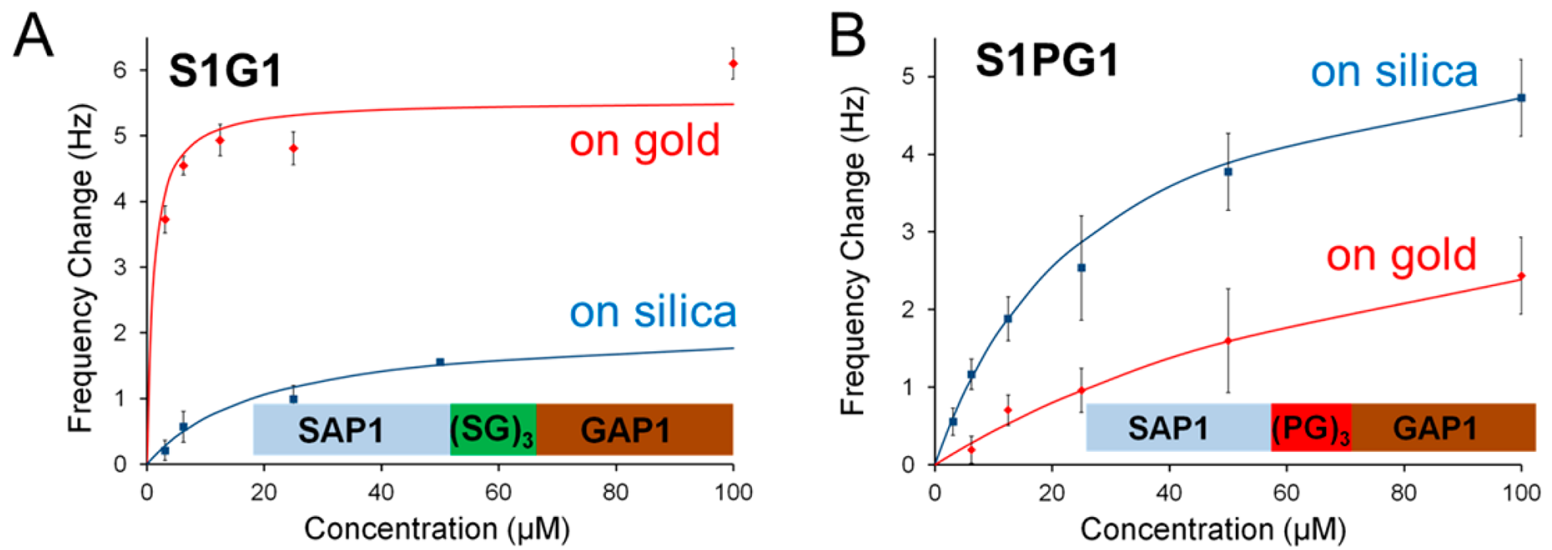

Figure 1. Adsorption data points of the S1G1 (A) and S1PG1 (B) peptides fitted to a single Langmuir adsorption model. The effect of using a rigid vs soft linker on the binding affinity of the hybrid S1G1 peptide is presented. Red dots and dark blue dots represent the frequency shifts upon mass deposition on the QCM-D sensor during the adsorption of the peptides on a gold coated sensor surface or a silica coated sensor surface, respectively. Continuous red lines and dark blue lines are the model fits to the adsorption data points of peptides on gold or silica surface, respectively. Error bars represent standard deviations from three independent adsorption experiments at each concentration.
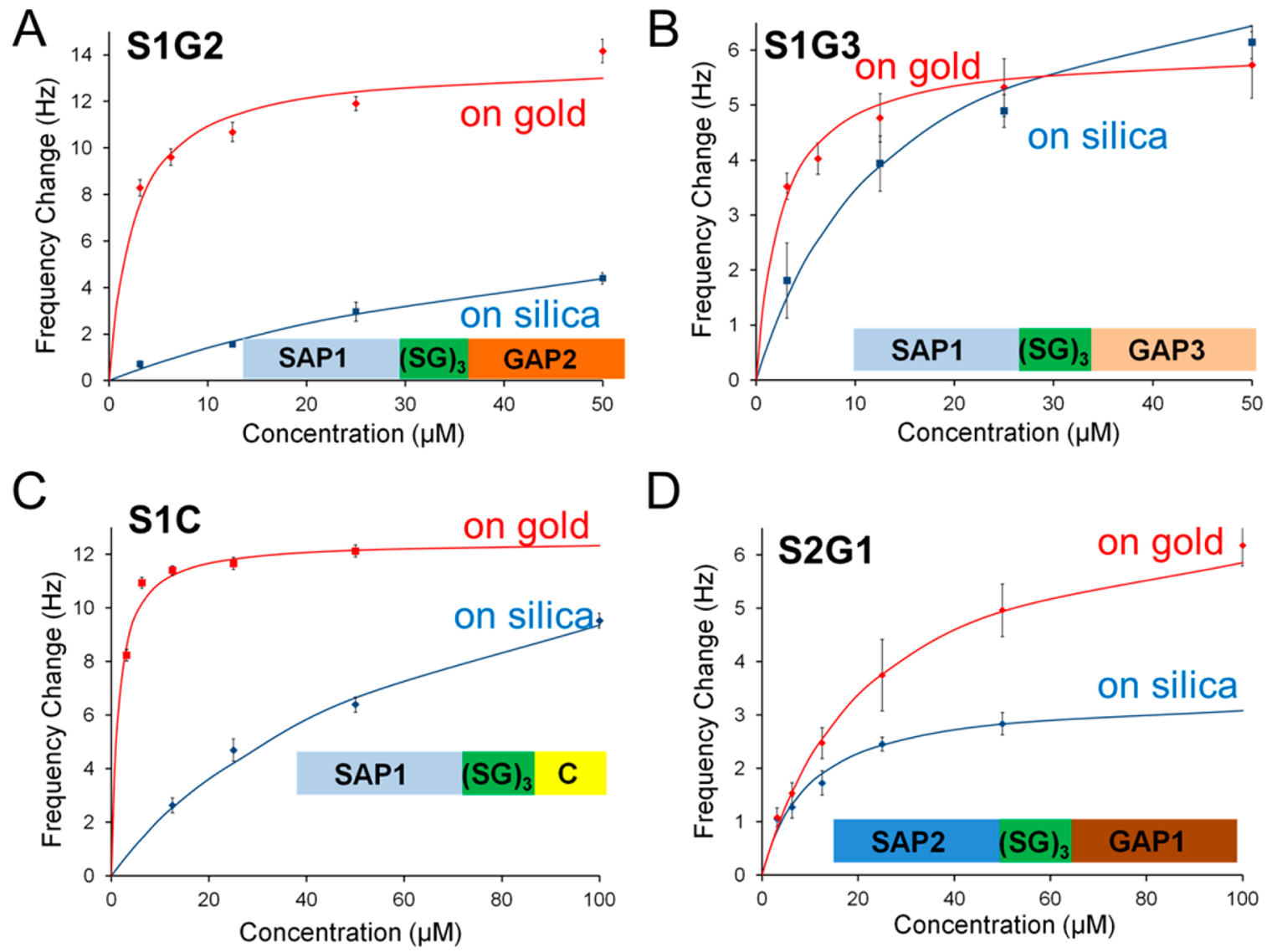

D

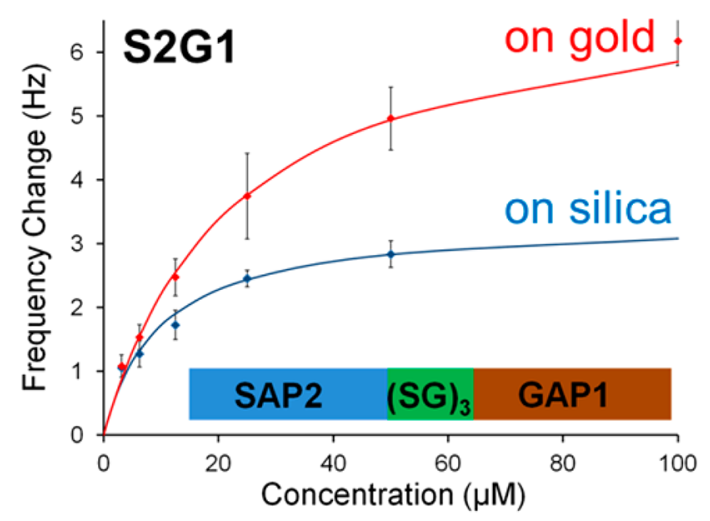

Figure 2. Adsorption data points of the S1G2, S1G3, S1C, and S2G1 peptides on silica and gold surfaces. Gold binding part of the S1G1 hybrid peptide was changed in (A), (B), and (C). Silica binding part of the S1G1 peptide was changed in (D). Data points are fitted to a single Langmuir adsorption model. Red dots and dark blue dots represent the frequency shifts upon mass deposition on QCM-D sensor during the adsorption of the peptides on a gold coated sensor surface or a silica coated sensor surface, respectively. Continuous red lines and dark blue lines are the model fits to the adsorption data points of peptides on gold or silica surface, respectively. Error bars represent standard deviations from three independent adsorption experiments at each concentration.

linker residues between the gold binding and silica binding parts of the hybrid peptide were replaced with a rigid linker, PGPGP. The rigidity of the PGPGP linker arises from extended structures resulting in elbow bending dynamics and proline turns. ${ }^{31}$ S1PG1 peptide derived from S1G1 peptides by rigid linker replacement. S1PG1's silica binding affinity was compromised, whereas the binding affinity to the gold surface remained same. Introducing a rigid linker can decrease the degree of freedom of the hybrid S1PG1 peptide on silica and gold surfaces. Further design of the hybrid peptides was carried out using GSGSG linker to bridge the silica binding and gold binding peptides to build the hybrid peptides. 
Table 2. Binding Affinity Constants of the Hybrid Linkers on Gold and Silica Surfaces, Probed With QCM-D

\begin{tabular}{lccccc} 
& \multicolumn{2}{c}{ on gold surface } & & \multicolumn{2}{c}{ on silica surface } \\
\cline { 2 - 3 } \cline { 5 - 6 } peptide & $K_{\mathrm{D}}(\mu \mathrm{M})$ & $\Delta G\left(\mathrm{kcal} \mathrm{mol}^{-1}\right)$ & & $K_{\mathrm{D}}(\mu \mathrm{M})$ & $\Delta G\left(\mathrm{kcal} \mathrm{mol}^{-1}\right)$ \\
S1G1 & $20 \pm 2.5$ & $-6.0 \pm 0.7$ & & $1.0 \pm 0.2$ & $-8.1 \pm 0.1$ \\
S1G2 & $58 \pm 17$ & $-5.8 \pm 0.2$ & & $2.5 \pm 0.2$ & $-7.6 \pm 0.1$ \\
S1C & $87 \pm 39$ & $-5.5 \pm 0.3$ & & $1.4 \pm 0.2$ & $-8.0 \pm 0.1$ \\
S1G3 & $24 \pm 2.6$ & $-6.3 \pm 0.1$ & & $2.7 \pm 0.2$ & $-7.6 \pm 0.3$ \\
S2G1 & $9.7 \pm 1.0$ & $-6.8 \pm 0.2$ & & $323 \pm 7$ & $-6.4 \pm 0.2$ \\
S1PG1 & $24 \pm 1.0$ & $-6.3 \pm 0.1$ & & $100 \pm 27$ & $-5.4 \pm 0.2$ \\
\hline
\end{tabular}

Other hybrid peptides with different gold binding motifs, namely GAP2 and GAP3 were designed for affinity screening too. Additionally, instead of gold binding peptides, a single cysteine was used as the gold binding part in S1C peptide. Both GAP2, and GAP3 peptides are negatively charged and uncharged respectively. Gold binding affinity of the S1G2 peptide and S1C peptide were found lower compared to the binding affinity of S1G1. This might be observed due to the lower binding affinity of cysteine and GAP2 peptide to gold surface. S1G3 peptide which contains six histidine residues as gold binding domain was expected to have a good affinity to gold surface. Because histidine has an imidazole ring that is known to form a strong complex with semiconductors, metal ions and metal surfaces. ${ }^{32}$ In general gold binding affinities of all hybrid peptides were found lower compared to the native GAP1 and S1G1 peptide. Also the gold binding affinity of the S1G1 was found lower compared to the GAP1. These findings are indicating a constraint on the final hybrid peptide forms triggered by the attachment of two different peptides together. It was previously investigated that depending on the composition of the residues within a peptide, a structural constraint could led in a loss or a gain in binding affinity to a given solid material surface depending on amino acid chain. ${ }^{33,34}$

Silica binding peptide part of S1G1 was replaced with SAP2 silica binding peptide and S2G1 peptide was formed. SAP2 is a silica binding peptide that was selected from phage displayed peptide library. ${ }^{35}$ The gold binding affinity of the S2G1 is higher compared to the S1G1 peptide, but there is a dramatic decrease in the affinity of the peptide to the silica surface. The SAP2 peptide contains two methionine residues. Methionine residues were reported for their active role in gold binding affinity previously. ${ }^{36}$ So, methionine residues of SAP2 peptide could have increased the gold binding affinity of the S2G1 peptide. However this nonspecific increase in binding affinity is unwanted.

Analysis of the peptide films showed that hybrid peptides are forming rigid films both on the gold and silica surfaces. QCMD dissipation data given in Figure S2 in Supporting Information presents a low degree of water entrapment within the peptide film on silica/gold surface. This is a good indication that peptides form intact and resistant structures similar to that of self-assembled monolayers of the chemical thiols and silanes. ${ }^{37}$

Molecular interaction studies revealed that S1G1 is a strong, selective binder for gold and silica surfaces. Additionally, the specificity of the silica binding part (SAP1) and gold binding part (GAP1) of S1G1 was demonstrated as noted previously. ${ }^{21,38}$ Our search results for affinity screening of hybrid peptides with varying silica or gold binding peptides has indicated S1G1 as a good candidate for nanohybrid materials formation and building nanosystems. Surface coverage calculations for the peptides given in Figure S4 in Supporting
Information also validate $\mathrm{S} 1 \mathrm{G} 1$ as a suitable peptide for nanohybrid assemblies with having a large surface coverage fractions on both silica and gold surfaces.

Following the molecular interaction studies of S1G1, S1G1 peptide was utilized as an assembler for gold nanoparticle immobilization. First the silica surface was decorated with S1G1 peptide which was followed by the addition of gold nanoparticles (AuNPs). Assembly of S1G1 and AuNPs on the silica surface was monitored using QCM-D. Collected adsorption data for real time assembly of AuNPs is presented in Figure 3. A viscoelastic model was fitted to the frequency
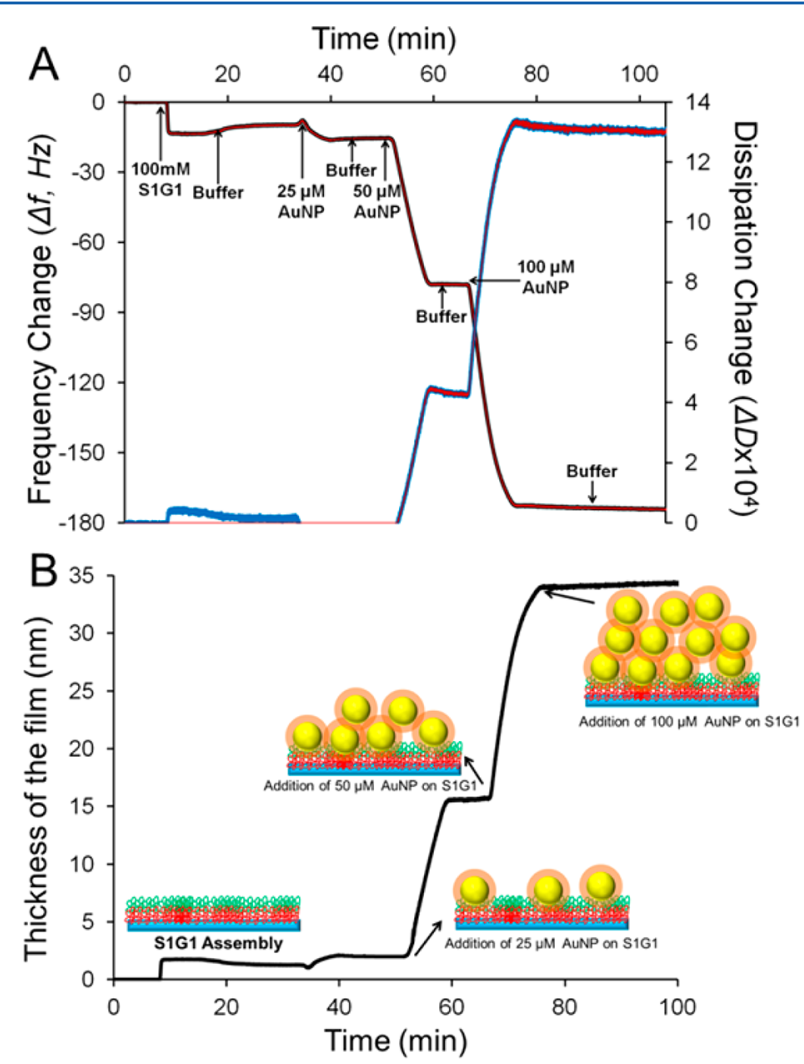

Figure 3. (A) Assembly of the gold nanoparticles on a S1G1 decorated silica surface. Real time adsorption data using quartz crystal microbalance dissipation monitoring; black lines represents the fitted viscoelastic model to the data points. (B) Gold nanoparticle film was formed on the S1G1 coated gold surface. Gold nanoparticle film thickness is increasing upon adsorption of the additional gold nanoparticles as a function of increasing gold nanoparticle concentration. Using the raw data in (A), gold nanoparticle film thickness was calculated.

change data and dissipation change data upon mass deposition collected by QCM-D. Using the viscoelastic modeling, Voigt model, the thickness of the gold nanoparticle film was calculated as $\sim 34 \mathrm{~nm}^{39,40}$ AuNPs with an increasing concentration filled the empty adsorption sites on the S1G1 assembled silica surface until equilibrium was reached. As the film was formed laterally, the amount of water molecules captured increases. This was reflected as an increase in the dissipation change in Figure 3A. The peptide film thickness of the $100 \mu \mathrm{M}$ S1G1 deposited on silica coated QCM-D sensor was $\sim 2 \mathrm{~nm}$. However, when $25 \mu \mathrm{M}$ AuNPs were injected onto the sensor surface, not a visible change was observed in the dissipation; this might be because a very low number of nanoparticles were captured on the surface. However, when 



Figure 4. XPS analysis of the S1G1 enabled silica film on gold surface. (A) Decay of the gold signal upon deposition of silica on gold surface by the catalysis of S1G1. (B) Oxygen signal from silica film. (C) Silica signal from silica film formed. (D) AFM image of the biosilica nanoparticle films formed on the gold surface catalyzed by the S1G1. (E) SEM image of the biosilica film formed on a large area. (F) Zoomed in morphology of the densely packed biosilica nanoparticles forming continuous biosilica film.

increasing the concentration by 2 -fold, a dramatic increase in the dissipation was observed which was reflected as $\sim 16 \mathrm{~nm}$ of increase in the film thickness, and increasing the AuNPs by 4fold the final $\sim 34 \mathrm{~nm}$ thickness was reached. Control experiments (given in Figure S3 in the Supporting Information) verified that the S1G1 modification of silica surface dramatically increased the amount of assembled gold particles on silica surface.

S1G1 peptide was also demonstrated as a material synthesizer using its multifunctionality both for assembly and material synthesis at the same time. To do so, silica formation was tested on a gold film for using the multifunctionality of the S1G1 peptide. S1G1 was first assembled on gold surface by drop-casting, following the washing steps to remove loosely bound excess peptide from the surface. Silica precursor molecule, hydrolyzed TMOS in $1 \mathrm{mM} \mathrm{HCl}$, was put on preformed S1G1 layer. The SAP1 part of the S1G1 peptide was expected to react with silane precursor and catalyze the formation of the silica. After its contact with the surface immobilized S1G1 peptide, silica formation was initiated and finalized by washing the precursor after $10 \mathrm{~min}$ of incubation. The removal of the precursor is crucial to prevent amorphous gel formation of unreacted silane precursor. Formation of the silica film was validated with XPS as given in Figure 4. Unmodified gold surface was used as the control group. XPS is a surface technique, so any film formation on the surface will be represented as a change in the initial surface signal intensity. ${ }^{41}$ In the XPS analysis, the $\mathrm{C} 1 \mathrm{~s}$ reference peak is set at $285 \mathrm{eV}$. The silica formation on $\mathrm{Au}$ is confirmed by XPS results. The peak at $\sim 103.97 \mathrm{eV}$ belongs to $\mathrm{SiO}_{2}$, and its presence is also confirmed by the presence of an oxygen peak at $\sim 533.33 \mathrm{eV}$. We have also observed a shift in Au peaks by $0.2 \mathrm{eV}$ in comparison to the control sample, suggesting S1G1 binding to $\mathrm{Au}$. Intensity of $\mathrm{Au}$ peak has decreased by huge amount, suggesting a thick silica film formation. Topography and structure of silica film formed on gold surface were investigated using AFM and SEM. AFM analysis revealed that silica film was formed. The focused SEM image in Figure 4F shows that continuous silica film was formed with a continuous nanoparticle assembly-like morphology. This observation is in agreement with previous findings that suggests SAP1 is forming silica nanoparticles. ${ }^{25}$ The SEM image verifies that silica film was formed as a densely packed film of silica nanoparticles with an approximate size of $50 \mathrm{~nm}$.

\section{CONCLUSIONS}

Proteins play a vital role in the biomaterial formation within the living organisms in the form of hard tissues. To mimic Nature's way for material formation, combinatorial libraries of phage and bacteria displaying short peptides have been screened and selected for both material synthesis and nanomaterial assembly. Here the design and implementation of a dual functionality peptide for nanohybrid assembly was presented. All of the tests for the binding affinity were carried out under the assembly conditions of the peptides for possible nanotechnology applications. Silica affinity peptides and gold affinity peptides were combined together through a flexible linker. Variations of silica binding peptides and gold binding peptides hybrids were formed and tested for their binding affinities to a silica surface and to a gold surface. S1G1 hybrid peptide was selected as the final hybrid peptide. Dissipation change recorded during the adsorption of the peptides on silica/gold surface during QCM$\mathrm{D}$ experiments showed that peptide films contain a low amount of water; in other words, tight peptide films are formed on the silica/gold surface. This low degree of water entrapment may trigger the homogeneous peptide layer adsorption on the materials surfaces. Previous studies on the supramolecular assembly of the GAP1 peptide on the gold surface have revealed that the growth of the peptide film goes through a series of transitions. ${ }^{42}$ First, GAP1 peptide molecules are adsorbed on the surface and as a function of the increasing peptide concentration islands are formed. Second diffusion 
process takes place and finally fiber networks of the peptide layer are formed to cover the surface. The final peptide film has a low degree of the surface roughness on the given solid surface. These properties of the peptide film may help the formation of a tight surface structure.

Multifunctional linker design for nanohybrid assembly needs complex work and optimization. Here we proposed and implemented a rational route for this design and presented the dual functionality of the peptide. This approach can be extended and be utilized for the design of new generation hybrid functional peptides, while the specificity of each peptide is being conserved. Multifunctional peptides will enable creating complex nanostructures at single step or hybrid materials synthesis in a single pot. On-chip applications for optoelectronics, bionanotechnology, and biomedical assay for diagnosis can benefit a lot from single step nanoassembly enabled by hybrid peptides.

\section{ASSOCIATED CONTENT}

\section{S Supporting Information}

Physicochemical properties of individual peptides, adsorption isotherms of bifunctional peptides on gold or silica surfaces, dissipation data of the bifunctional peptide films adsorbed on gold or silicasurface, control experiments for nanoparticle assembly, surface coverage calculations of the peptides. This material is available free of charge via the Internet at http:// pubs.acs.org

\section{AUTHOR INFORMATION}

\section{Corresponding Authors}

*E-mail: urartu@mit.edu (U.O.S.S.).

*E-mail: volkan@stanfordalumni.org (H.V.D.)

\section{Present Address}

${ }^{\S}$ U.O.S.S.: Massachusetts Institute of Technology, Synthetic Biology Center, 500 Technology Square, NE47-257, Cambridge MA, USA.

\section{Notes}

The authors declare no competing financial interest.

\section{ACKNOWLEDGMENTS}

This work is supported in part by NRF-CRP-6-2010-02 and NRF-RF-2009-09, BMBF TUR 09/001, and TUBITAK EEEAG, 109E002, 109E004, 110E010, and 110E217. H.V.D. acknowledges support from ESF-EURYI and TUBA-GEBIP.

\section{REFERENCES}

(1) Douglas, S. M.; Dietz, H.; Liedl, T.; Hogberg, B.; Graf, F.; Shih, W. M. Self-assembly of DNA into nanoscale three-dimensional shapes. Nature 2009, 459 (7245), 414-418.

(2) Zhang, S. G. Fabrication of Novel Biomaterials through Molecular Self-Assembly. Nat. Biotechnol. 2003, 21 (10), 1171-1178.

(3) Nabika, H.; Oikawa, T.; Iwasaki, K.; Murakoshi, K.; Unoura, K. Dynamics of Gold Nanoparticle Assembly and Disassembly Induced by pH Oscillations. J. Phys. Chem. C 2012, 116 (10), 6153-6158.

(4) Love, J. C.; Estroff, L. A.; Kriebel, J. K.; Nuzzo, R. G.; Whitesides, G. M. Self-Assembled Monolayers of Thiolates on Metals As a Form of Nanotechnology. Chem. Rev. 2005, 105 (4), 1103-1169.

(5) Krauland, E. M.; Peelle, B. R.; Wittrup, K. D.; Belcher, A. M. Peptide Tags for Enhanced Cellular and Protein Adhesion to SingleCrystal Line Sapphire. Biotechnol. Bioeng. 2007, 97 (5), 1009-1020.

(6) Naik, R. R.; Cui, Y.; Kim, S. N.; Jones, S. E.; Wissler, L. L.; McAlpine, M. C. Chemical Functionalization of Graphene Enabled by Phage Displayed Peptides. Nano Lett. 2010, 10 (11), 4559-4565.
(7) Tang, Z.; Palafox-Hernandez, J. P.; Law, W. C.; Hughes, Z. E.; Swihart, M. T.; Prasad, P. N.; Knecht, M. R.; Walsh, T. R. Biomolecular Recognition Principles for Bionanocombinatorics: An Integrated Approach To Elucidate Enthalpic and Entropic Factors. ACS Nano 2013, 7, 9362-9346.

(8) Kim, S. N.; Slocik, J. M.; Naik, R. R. Strategy for the Assembly of Carbon Nanotube-Metal Nanoparticle Hybrids Using Biointerfaces. Small 2010, 6, 1992-1995.

(9) Pacardo, D. B.; Sethi, M.; Jones, S. E.; Naik, R. R.; Knecht, M. R. Biomimetic synthesis of $\mathrm{Pd}$ nanocatalysts for the Stille coupling reaction. ACS Nano 2009, 3 (5), 1288-1296.

(10) Rothenstein, D.; Claasen, B.; Omiecienski, B.; Lammel, P.; Bill, J. Isolation of $\mathrm{ZnO}$-Binding 12-mer Peptides and Determination of Their Binding Epitopes by NMR Spectroscopy. J. Am. Chem. Soc. 2012, 134 (30), 12547-12556.

(11) Ikeda, T.; Ninomiya, K.; Hirota, R.; Kuroda, A. Single-Step Affinity Purification of Recombinant Proteins Using the Silica-Binding Si-tag as a Fusion Partner. Protein Expression Purif. 2010, 71 (1), 9195.

(12) Estephan, E.; Larroque, C.; Bec, N.; Martineau, P.; Cuisinier, F. J.; Cloitre, T.; Gergely, C. Selection and Mass Spectrometry Characterization of Peptides Targeting Semiconductor Surfaces. Biotechnol. Bioeng. 2009, 104 (6), 1121-1131.

(13) Curtis, S. B.; Hewitt, J.; MacGiliivray, R. T. A.; Dunbar, W. S. Biomining With Bacteriophage: Selectivity of Displayed Peptides for Naturally Occurring Sphalerite and Chalcopyrite. Biotechnol. Bioeng. 2009, 102 (2), 644-650.

(14) Date, T.; Sekine, J.; Matsuno, H.; Serizawa, T. Polymer-Binding Peptides for the Noncovalent Modification of Polymer Surfaces: Effects of Peptide Density on the Subsequent Immobilization of Functional Proteins. ACS Appl. Mater. Interfaces 2011, 3 (2), 351-359.

(15) Lee, Y. J.; Yi, H.; Kim, W. J.; Kang, K.; Yun, D. S.; Strano, M. S.; Ceder, G.; Belcher, A. M. Fabricating Genetically Engineered HighPower Lithium-Ion Batteries Using Multiple Virus Genes. Science 2009, 324 (5930), 1051-1055.

(16) Sano, K.; Yoshii, S.; Yamashita, I.; Shiba, K. In Aqua Structuralization of a Three-Dimensional Configuration Using Biomolecules. Nano Lett. 2007, 7 (10), 3200-3202.

(17) Slocik, J. M.; Naik, R. R. Probing Peptide-Nanomaterial Interactions. Chem. Soc. Rev. 2010, 39 (9), 3454-3463.

(18) Sethi, M.; Pacardo, D. B.; Knecht, M. R. Biological Surface Effects of Metallic Nanomaterials for Applications in Assembly and Catalysis. Langmuir 2010, 26 (19), 15121-15134.

(19) Nochomovitz, R.; Amit, M.; Matmor, M.; Ashkenasy, N. Bioassisted multi-nanoparticle patterning using single-layer peptide templates. Nanotechnology 2010, 21 (14), 145305.

(20) Liu, C.; Jiang, Z. Y.; Tong, Z. W.; Li, Y. X.; Yang, D. Biomimetic Synthesis of Inorganic Nanocomposites by a De Novo Designed Peptide. RSC Adv. 2014, 4 (1), 434-441.

(21) Kim, J.; Myung, N. V.; Hur, H. G. Peptide Directed Synthesis of Silica Coated Gold Nanocables. Chem. Commun. 2010, 46 (24), $4366-4368$

(22) Yazici, H.; Fong, H.; Wilson, B.; Oren, E. E.; Amos, F. A.; Zhang, H.; Evans, J. S.; Snead, M. L.; Sarikaya, M.; Tamerler, C. Biological response on a titanium implant-grade surface functionalized with modular peptides. Acta Biomater. 2013, 9 (2), 5341-5352.

(23) Gungormus, M.; Branco, M.; Fong, H.; Schneider, J. P.; Tamerler, C.; Sarikaya, M. Self Assembled Bi-Functional Peptide Hydrogels with Biomineralization-Directing Peptides. Biomaterials 2010, 31 (28), 7266-7274.

(24) Bonde, J. S.; Bulow, L. One-Step Purification of Recombinant Human Amelogenin and Use of Amelogenin as a Fusion Partner. PLoS One 2012, 7 (3), e33269.

(25) Brott, L. L.; Naik, R. R.; Pikas, D. J.; Kirkpatrick, S. M.; Tomlin, D. W.; Whitlock, P. W.; Clarson, S. J.; Stone, M. O. Ultrafast Holographic Nanopatterning of Biocatalytically Formed Silica. Nature 2001, 413 (6853), 291-293.

(26) Brown, S. Metal-Recognition by Repeating Polypeptides. Nat. Biotechnol. 1997, 15 (3), 269-272. 
(27) Huang, Y.; Chiang, C. Y.; Lee, S. K.; Gao, Y.; Hu, E. L.; De Yoreo, J.; Belcher, A. M. Programmable Assembly of Nanoarchitectures Using Genetically Engineered Viruses. Nano Lett. 2005, 5 (7), 1429-1434.

(28) Yuca, E.; Karatas, A. Y.; Seker, U. O. S.; Gungormus, M.; DinlerDoganay, G.; Sarikaya, M.; Tamerler, C. In Vitro Labeling of Hydroxyapatite Minerals by an Engineered Protein. Biotechnol. Bioeng. 2011, 108 (5), 1021-1030.

(29) Seker, U. O. S.; Wilson, B.; Sahin, D.; Tamerler, C.; Sarikaya, M. Quantitative Affinity of Genetically Engineered Repeating Polypeptides to Inorganic Surfaces. Biomacromolecules 2009, 10 (2), 250-257.

(30) Tamerler, C.; Oren, E. E.; Duman, M.; Venkatasubramanian, E.; Sarikaya, M. Adsorption Kinetics of an Engineered Gold Binding Peptide by Surface Plasmon Resonance Spectroscopy and a Quartz Crystal Microbalance. Langmuir 2006, 22 (18), 7712-7718.

(31) Radford, S. E.; Laue, E. D.; Perham, R. N.; Miles, J. S.; Guest, J. R. Segmental Structure and Protein Domains in the Pyruvate Dehydrogenase Multienzyme Complex of Escherichia coli. Genetic Reconstruction in Vitro and ${ }^{1} \mathrm{H}-\mathrm{NMR}$ Spectroscopy. Biochem. J. 1987, 247 (3), 641-649.

(32) Seker, U. O. S.; Mutlugun, E.; Hernandez-Martinez, P. L.; Sharma, V. K.; Lesnyak, V.; Gaponik, N.; Eychmuller, A.; Demir, H. V. Bio-Nanohybrids of Quantum Dots and Photoproteins Facilitating Strong Nonradiative Energy Transfer. Nanoscale 2013, 5 (15), 70347040.

(33) Chen, H.; Su, X.; Neoh, K. G.; Choe, W. S. Context-Dependent Adsorption Behavior of Cyclic and Linear Peptides on Metal Oxide Surfaces. Langmuir 2009, 25 (3), 1588-1593.

(34) Seker, U. O. S.; Wilson, B.; Dincer, S.; Kim, I. W.; Oren, E. E.; Evans, J. S.; Tamerler, C.; Sarikaya, M. Adsorption Behavior of Linear and Cyclic Genetically Engineered Platinum Binding Peptides. Langmuir 2007, 23 (15), 7895-7900.

(35) Eteshola, E.; Brillson, L. J.; Lee, S. C. Selection and Characteristics of Peptides That Bind Thermally Grown Silicon Dioxide Films. Biomol. Eng. 2005, 22 (5-6), 201-204.

(36) Peelle, B. R.; Krauland, E. M.; Wittrup, K. D.; Belcher, A. M. Design Criteria for Engineering Inorganic Material-Specific Peptides. Langmuir 2005, 21 (15), 6929-6933.

(37) Diebod, R. M.; Clarke, D. R. Smooth, Aggregate-Free SelfAssembled Monolayer Deposition of Silane Coupling Agents on Silicon Dioxide. Langmuir 2012, 28 (44), 15513-15520.

(38) Tamerler, C.; Duman, M.; Oren, E. E.; Gungormus, M.; Xiong, X.; Kacar, T.; Parviz, B. A.; Sarikaya, M. Materials Specificity and Directed Assembly of a Gold-Binding Peptide. Small 2006, 2 (11), 1372-1378.

(39) Seker, U. O. S.; Ozel, T.; Demir, H. V. Peptide-Mediated Constructs of Quantum Dot Nanocomposites for Enzymatic Control of Nonradiative Energy Transfer. Nano Lett. 2011, 11 (4), 1530-1539.

(40) Hook, F.; Kasemo, B.; Nylander, T.; Fant, C.; Sott, K.; Elwing, H. Variations in Coupled Water, Viscoelastic Properties, And Film Thickness of a Mefp-1 Protein Film during Adsorption and CrossLinking: A Quartz Crystal Microbalance with Dissipation Monitoring, Ellipsometry, and Surface Plasmon Resonance Study. Anal. Chem. 2001, 73 (24), 5796-5804.

(41) Moulder, J. F.; Chastain, J. Handbook of X-ray Photoelectron Spectroscopy: A Reference Book of Standard Spectra for Identification and Interpretation of XPS Data; Physical Electronics Division, Perkin-Elmer Corp.: Eden Prairie, MN, 1992; p 261.

(42) So, C. R.; Tamerler, C.; Sarikaya, M. Adsorption, Diffusion, and Self-Assembly of an Engineered Gold-Binding Peptide on $\mathrm{Au}(111)$ Investigated by Atomic Force Microscopy. Angew. Chem., Int. Ed. 2009, 48 (28), 5174-5177. 